\title{
Seepage Behaviour of Fractured Rock Mass Infilling Using Different Transfixion Rates under Cyclic Loading
}

\author{
Shuren Wang $\mathbb{D}^{1,2}$ Jiyun Zhang, ${ }^{1} \mathrm{Zhichao} \mathrm{Li}^{1}{ }^{1}$ and Yongqiang $\mathrm{Yu}^{1}$ \\ ${ }^{1}$ International Joint Research Laboratory of Henan Province for Underground Space Development and Disaster Prevention, \\ Henan Polytechnic University, Jiaozuo 454003, China \\ ${ }^{2}$ School of Minerals and Energy Resources Engineering, University of New South Wales, Sydney, NSW 2052, Australia
}

Correspondence should be addressed to Shuren Wang; w_sr88@163.com

Received 14 March 2021; Revised 3 April 2021; Accepted 7 April 2021; Published 10 May 2021

Academic Editor: Feng Xiong

Copyright (c) 2021 Shuren Wang et al. This is an open access article distributed under the Creative Commons Attribution License, which permits unrestricted use, distribution, and reproduction in any medium, provided the original work is properly cited.

It is very important to determine the seepage behaviour of fractured rock mass infilling to evaluate the stability of the surrounding rock. The joint transfixion rate is the ratio of the unpenetrated length to the penetration length of a joint in a sample. Samples of the fractured rock mass infilling using different transfixion rates were prepared, and a TCQT-III low-permeability coal-rock triaxial seepage device was used to conduct three cycles of confining pressure-seepage coupling tests. Results show that the permeability is a power function in the confining pressure of the sample, and the permeability changes most significantly with the confining pressures. The permeability of the sample increases exponentially with the joint transfixion rate. The permeability loss is positively correlated with the plastic deformation of the sample; the permeability changes most significantly during the first cycle loading. There is over $60 \%$ recovery of the permeability of the sample under cyclic loading for loads that do not exceed the strength of the infilling. The stress sensitivity coefficient decreases as the confining pressure increases and is higher during the unloading stage than that during the loading stage for samples with an incomplete transfixion rate. The conclusions obtained in this study can serve as a reference for grouting applications.

\section{Introduction}

The permeability of a jointed rock mass is closely related to the degree of joint filling and penetration [1-5]. The filling of joints in surrounding rock for underground engineering is characterized by random gap widths, occurrence complexity, and uncertainty in the transfixion rate, all of which significantly affect the permeability, shear strength, and stability of a rock mass [6-11]. The filling in a jointed and fractured rock mass is affected by the stress environment and usually undergoes an opening-closing-opening cycle which has a well-defined self-regulation ability. The fractured rock mass infilling is a unique and complex subject that is being actively researched.

Levasseur et al. proposed an evolution model for the permeability tensor based on the tensile strain of a joint fracture, which was assumed to occur along the principal strain direction [12]. Li et al. investigated the variation law of permeability of the shear rock under normal stiffness conditions, and they found that the increase of permeability was basically consistent with the increment of the hydraulic pressure [13]. Takemura et al. developed a semiempirical formula to correlate the permeability of a fractured rock mass with the particle size and porosity of the filling [14]. Ye et al. constructed a seepage model for filling a fractured rock mass and obtained an expression for the spatial seepage velocity [15]. Wang et al. tested the permeability for coal samples of different heights under cyclic loading and found that the permeability loss rate increased with the height-to-diameter ratio of the coal samples [16]. Mamot et al. used ice as a fracture filler and developed an improved Mohr-Coulomb failure criterion for specimens based on temperature and stress effects [17].

The results of a direct shear test conducted by Salimian et al. showed that the shear strength of a fractured rock mass decreased as the filling thickness increased [18]. Indraratna et al. proposed a normalized shear strength model for the fractured rock mass infilling, which showed that the physical 
properties of the rock mass and filling affect the shear strength [19]. Jahanian and Sadaghiani found that using soft materials to fill fractures weakens the shear strength of a rock mass: the shear strength of a rock mass was found to decrease gradually as the filling ratio increased [20]. Lu et al. reported that the shear strength and stiffness of a rock mass were affected above a critical filling thickness and used the results of numerical simulations and indoor tests to develop an empirical formula for the peak shear strength of a rock mass [21]. She and Sun defined three new parameters that were independent of the measuring scale to characterize the three-dimensional shape of a fractured surface and studied the mechanical properties of a filled fractured rock mass [22].

The difficulty of treating the complexity and randomness of fillings has hindered the development of rock mechanics $[23,24]$. Recently, 3D printing technology has been gradually applied to this problem [25]. Zhao et al. used 3D printing technology to produced five types of filled fractured rock samples and reported a W-shaped stress sensitivity coefficient for the permeability during the unloading of the confining pressure [26]. Wang et al. used the standard JRC profile curve to construct rock samples with different levels of roughness and gap widths: the higher the roughness was, the higher the permeability under low confining pressures was, and this phenomenon gradually disappeared with increasing confining pressure [27]. Head and Vanorio used 3D printing to construct a filled/fractured rock mass and measured the porosity, pore structure, permeability, fracture deformation, and fluid migration changes of the rock mass [28].

The joint transfixion rate is the ratio of the unpenetrated length to the penetration length of a joint in a sample. No studies have been published on seepage behaviour under cyclic loading for a fractured rock mass infilling with different transfixion rates. The fractured rock sample infilling with different transfixion rates were prepared considering the complex structural stress and joint fracture development in the surrounding rock of the Gaoligongshan railway tunnel, and the permeability and stress sensitivity coefficient of the samples were measured under cyclic variations in the confining pressure. The results serve as a reference for grouting construction in tunnel engineering.

\section{Materials and Method}

2.1. Engineering Background. The Gaoligongshan railway tunnel is located in Baoshan City, Yunnan province, China, and has a total length of $34.5 \mathrm{~km}$, a maximum buried depth of $1155 \mathrm{~m}$, and an average depth of $800 \mathrm{~m}$. The railway line is located in the collision zone between the Indian and Eurasian plates, which is affected by tectonic compression, resulting in a rock mass with poor integrity. Fractures and fold structures have developed, and there is severe differential weathering. Tunnel excavation has exposed many filled joint fractures with irregular transfixion rates.

Different transfixion rates frequently produce permeability variations in a fractured rock mass, which typically affects the grouting support mode and waterproof measures during different stages of construction. Research and engineering case studies show that the failure of a rock mass is mainly related to the evolution, expansion, and transfixion rate of original fractures [29-32]. Studying the seepage behaviour of a fractured rock mass with different transfixion rates under an engineering disturbance load has the considerable practical significance for grouting construction in tunnel engineering.

2.2. Sample Preparation. Fabricating a precision fracture insert was critical for the experimental study. A detachable cylindrical mould with an internal diameter of $50 \mathrm{~mm}$ and a height of $100 \mathrm{~mm}$ was used in conjunction with 3D printing technology to produce four $100 \mathrm{~mm} \times 50 \mathrm{~mm} \times 2 \mathrm{~mm}$ fracture inserts.

The insert was placed at different depths in the mould to produce four sample types with transfixion rates of $25 \%$, $50 \%, 75 \%$, and $100 \%$; the detailed procedure is described below.

(1) To ensure smooth demoulding of the sample, industrial vaseline was evenly smeared inside the mould and over the insert, and the insert was then placed at the geometric centre of the mould

(2) The sample blocks were constructed by filtering ordinary Portland cement 42.5R through a $0.5 \mathrm{~mm}$ diameter sieve mesh to ensure complete cement hydration. The mass ratio of cement, water, an antipermeable admixture, a waterreducing admixture, and an antifoamer was $1: 0.3: 0.015: 0.015: 0.003$. The solid material was evenly mixed, water was added under continuous stirring, and the mould was placed on a shaker while the slurry was poured into the mould to ensure the mould was completely filled. The average uniaxial compressive strength of three samples without the filling material under standard curing was measured to be $82.94 \mathrm{MPa}$

(3) After the sample block was poured and subjected to standard curing for $72 \mathrm{~h}$, the joint insert was slowly removed, and a filler slurry was poured into the fissure. The filling materials were simulated using a mixed slurry containing gypsum, river sand, water, a water-reducing admixture, and an antifoamer in a mass ratio of $1: 0.8: 0.38: 0.015: 0.003$, following the pouring and vibrating process described in step (2). The slurry contained river sand with a diameter below $0.3 \mathrm{~mm}$ as the aggregate and gypsum as the adhesive and exhibited strong water permeability, high porosity, and a well-defined strength and compressibility. Three samples composed of only gypsum and the sand slurry were poured at the same time, and the average uniaxial compressive strength was measured after standard curing to be $14.13 \mathrm{MPa}$, which was 0.17 times the strength of the rock block and used to distinguish between the performances of the sample block and the filler 


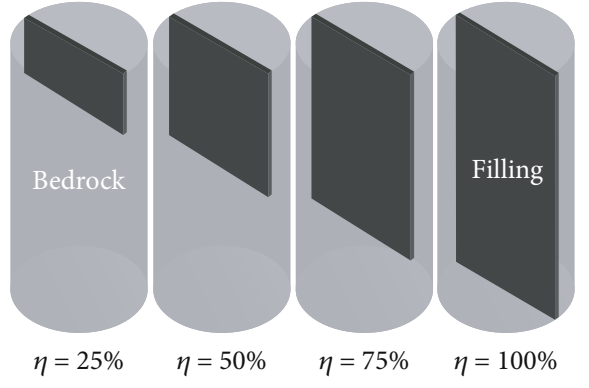

(a) Profile

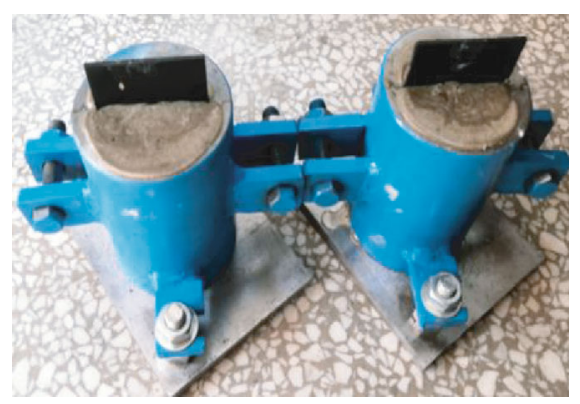

(b) Manufacturing mode

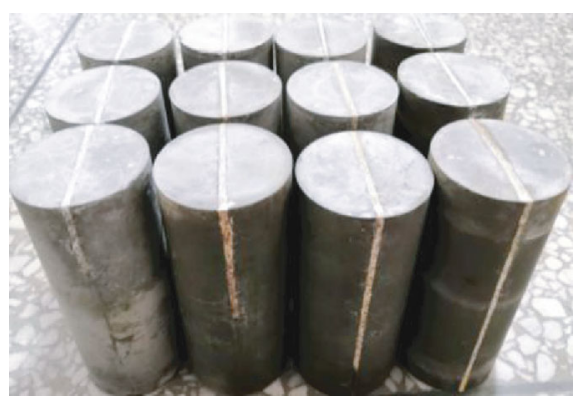

(c) Test samples

Figure 1: Sample production.

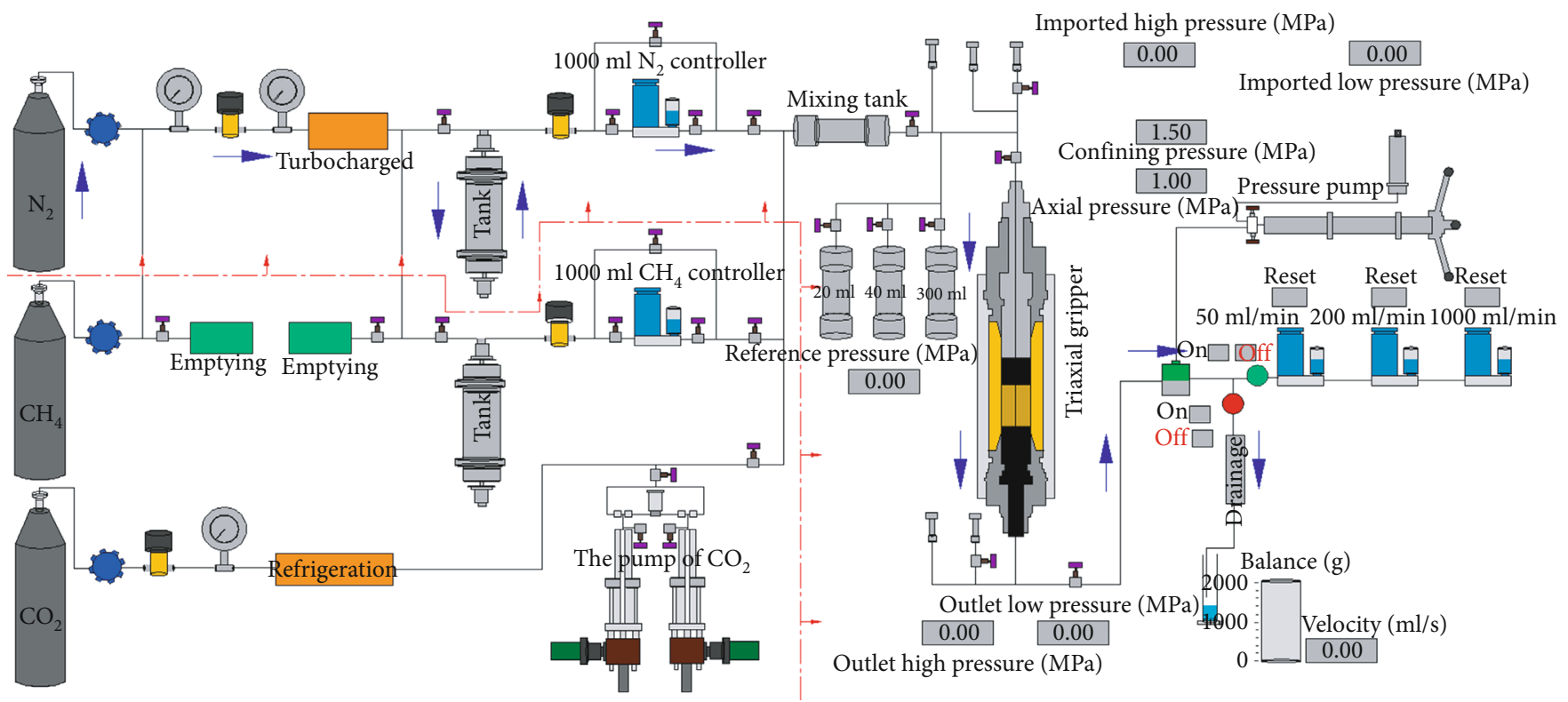

FIGURE 2: Test system and equipment.

(4) The mould was removed $24 \mathrm{~h}$ after completing the abovementioned steps, and standard curing was continued for $28 \mathrm{~d}$ to complete sample production. The samples were cut and polished until the unevenness at both ends was less than $0.05 \mathrm{~mm}$ and the precision requirements were met

A total of twelve samples were fabricated following the steps outlined above, with three samples for each transfixion rate; the production process and a portion of the complete sample set are shown in Figure 1. Some samples were selected for test analysis, and the samples with $100 \%, 75 \%, 50 \%$, and $25 \%$ transfixion rates were labelled $\mathrm{D}_{1}, \mathrm{D}_{2}, \mathrm{D}_{3}, \mathrm{E}_{1}, \mathrm{E}_{2}, \mathrm{E}_{3}$; $F_{1}, F_{2}, F_{3}$; and $G_{1}, G_{2}, G_{3}$, respectively.

2.3. Instrument and Test Procedure. A permeability test was carried out using a TCQT-III low-permeability coal-rock triaxial seepage device at Henan Polytechnic University, Jiaozuo City, China. The device is shown in Figure 2: the main components were a gas pressurized injection system, a system for automatically tracking the confining and axial pressures, a sample clamping device, a system for 


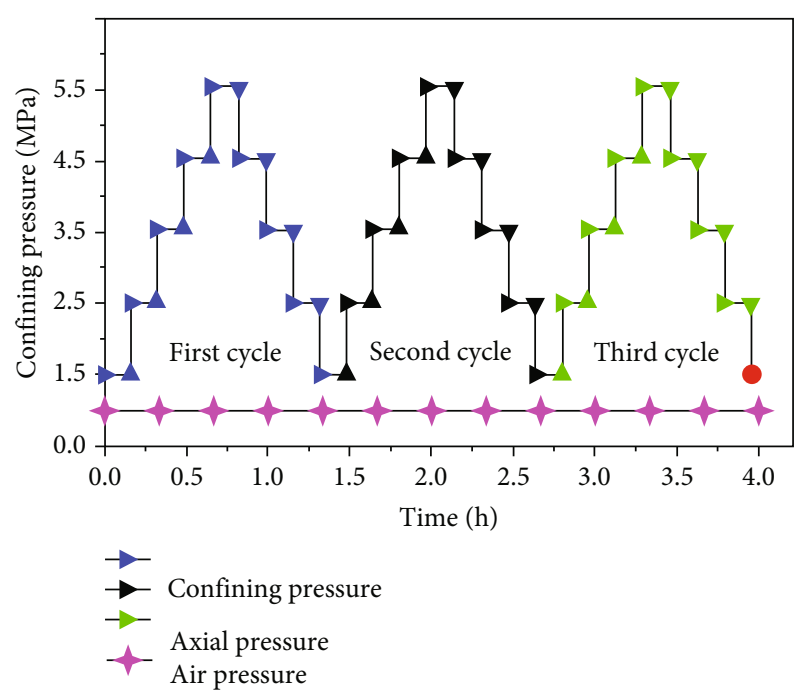

FIGURE 3: Cyclic confining pressure loading and unloading paths.

TABLE 1: Selected sample parameters.

\begin{tabular}{lcccc}
\hline No. & Height $(\mathrm{mm})$ & Diameter $(\mathrm{mm})$ & Weight $(\mathrm{g})$ & Density $\left(\mathrm{g} / \mathrm{cm}^{3}\right)$ \\
\hline $\mathrm{G}_{1}$ & 97.23 & 49.83 & 390.89 & 2.06 \\
$\mathrm{G}_{2}$ & 97.22 & 49.67 & 385.39 & 2.04 \\
$\mathrm{G}_{3}$ & 97.15 & 49.51 & 383.53 & 2.05 \\
$\mathrm{~F}_{1}$ & 98.26 & 49.81 & 394.62 & 2.06 \\
$\mathrm{~F}_{2}$ & 97.12 & 49.75 & 390.90 & 2.07 \\
$\mathrm{~F}_{3}$ & 96.70 & 49.75 & 383.68 & 2.04 \\
$\mathrm{E}_{1}$ & 96.25 & 49.60 & 385.09 & 2.07 \\
$\mathrm{E}_{2}$ & 96.56 & 49.62 & 386.30 & 2.06 \\
$\mathrm{E}_{3}$ & 93.51 & 49.90 & 373.64 & 2.04 \\
$\mathrm{D}_{1}$ & 96.98 & 49.75 & 385.24 & 2.04 \\
$\mathrm{D}_{2}$ & 98.16 & 49.76 & 390.41 & 2.04 \\
$\mathrm{D}_{3}$ & 98.13 & 49.75 & 388.73 & 2.03 \\
\hline
\end{tabular}

metering the inlet and outlet flows, a pressure measurement system, a system for performing a gas component analysis, and a data collection and processing system. $\mathrm{N}_{2}$ was used as the test gas in the study. The sample gripper had a diameter of $50 \mathrm{~mm}$ and a length of $50-100 \mathrm{~mm}$; the range of axial and confining pressures during loading was 0-80 MPa.

The confining pressure was considered to be low when the applied confining pressure was below the strength of the filling material. Experiments were performed to determine the seepage behaviour of the filled samples with different transfixion rates under low confining pressures. A sample in a triaxial stress state was loaded into the sample clamping device. To prevent water leakage between the sample and the rubber sleeve, the loading confining pressure was set to $1.5 \mathrm{MPa}$, and both the axial pressure and the inlet air pressure were set to $1.0 \mathrm{MPa}$. The outlet air pressure was atmospheric pressure, and only the confining pressure was changed during the entire test process.

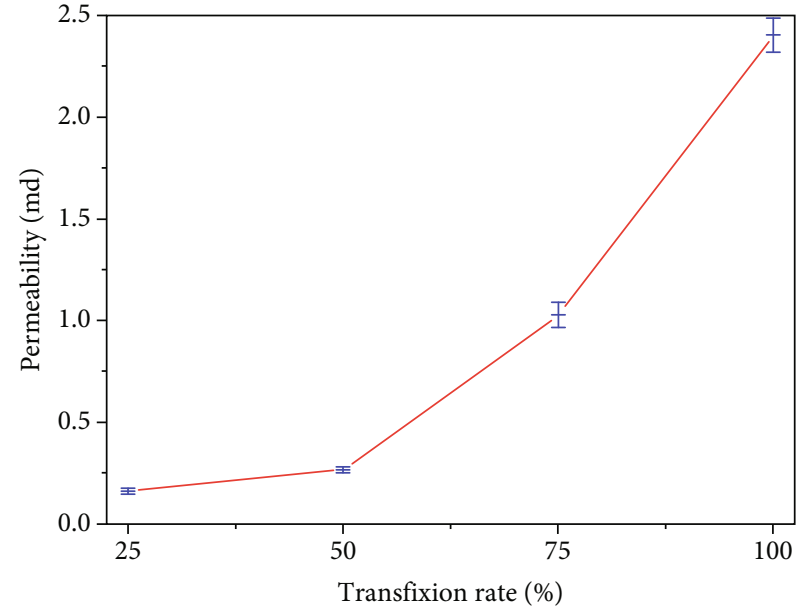

FIgURE 4: Permeability uniformity curve for different transfixion rates.

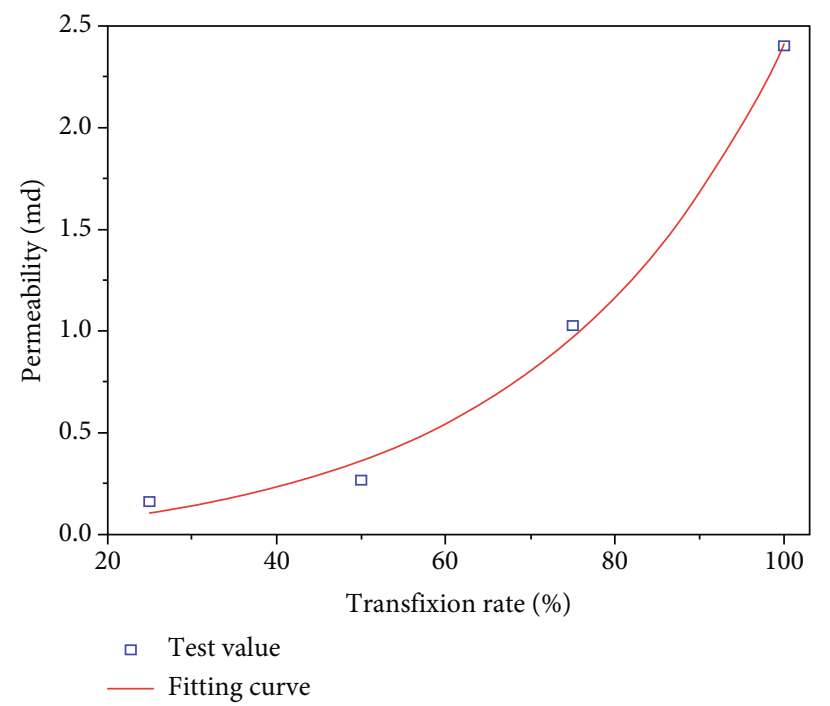

Figure 5: Relationship between permeability and transfixion rate.

The $\mathrm{N}_{2}$ was injected into the sample clamping device, and after the gas flow stabilized, the data acquisition system was turned on to record data every $30 \mathrm{~s}$. The confining pressure was loaded to $2.5 \mathrm{MPa}$ after the permeability remained stable for approximately $15 \mathrm{~min}$. The abovementioned operations were repeated until the confining pressure increased to $5.5 \mathrm{MPa}$, thus completing the loading process. During the unloading process, the axial pressure was maintained constant, and only the confining pressure was unloaded every 1.0 MPa down to $1.5 \mathrm{MPa}$, thus completing the first loading and unloading cycle of the test. The second and third cycles of the permeability test were performed following the abovementioned method. The test was completed when the third cycle was unloaded to 1.5 MPa. The loading and unloading paths of the test are shown in Figure 3.

2.4. Theoretical Approach. A rock mass has a complex and changing internal structure; the seepage fluid must satisfy 


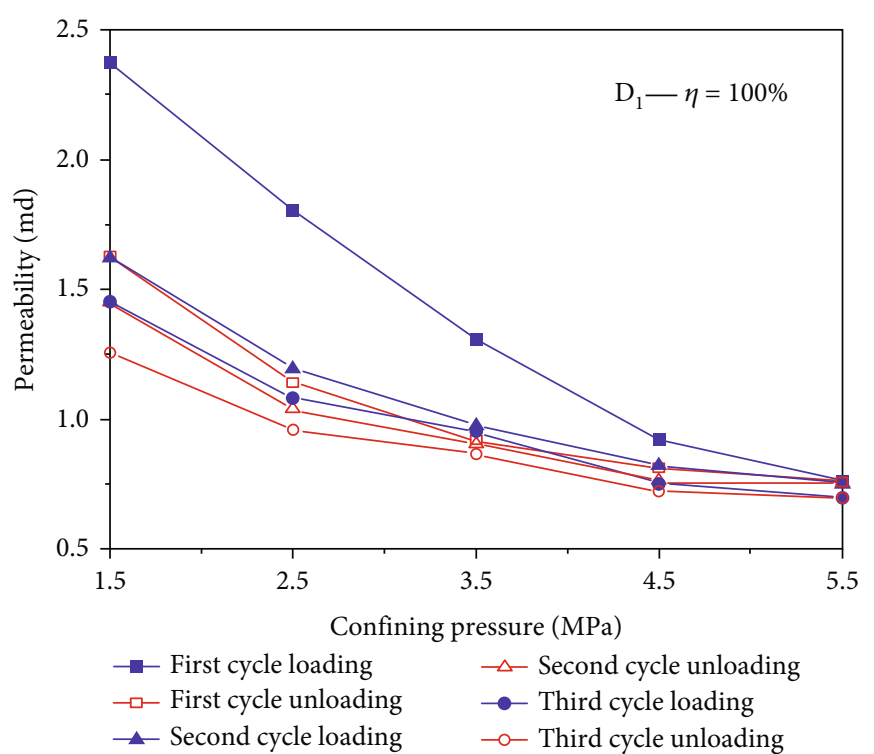

(a) $\eta=100 \%$

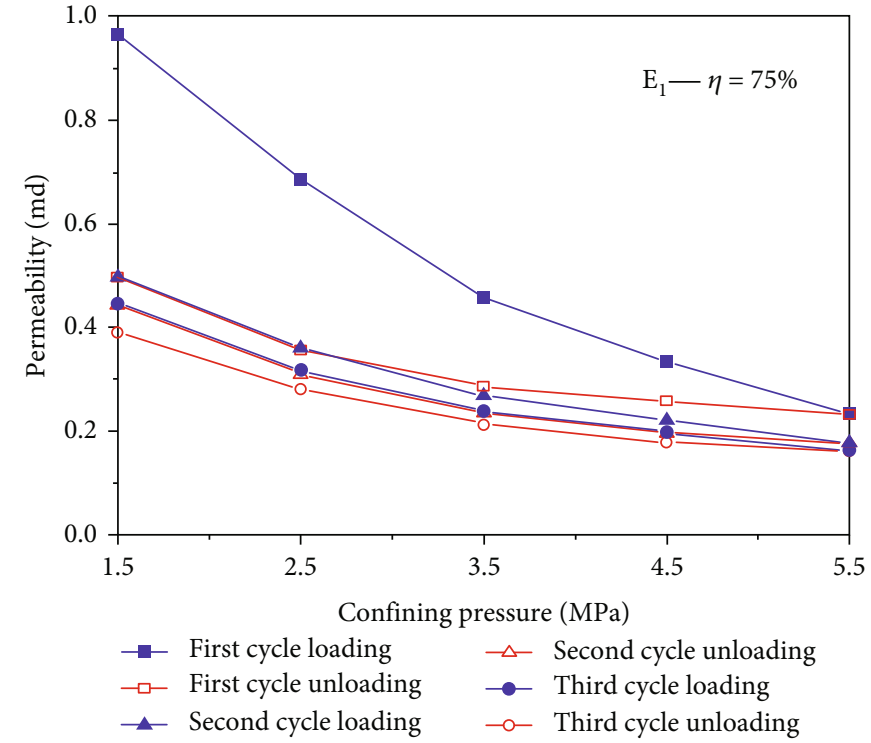

(b) $\eta=75 \%$

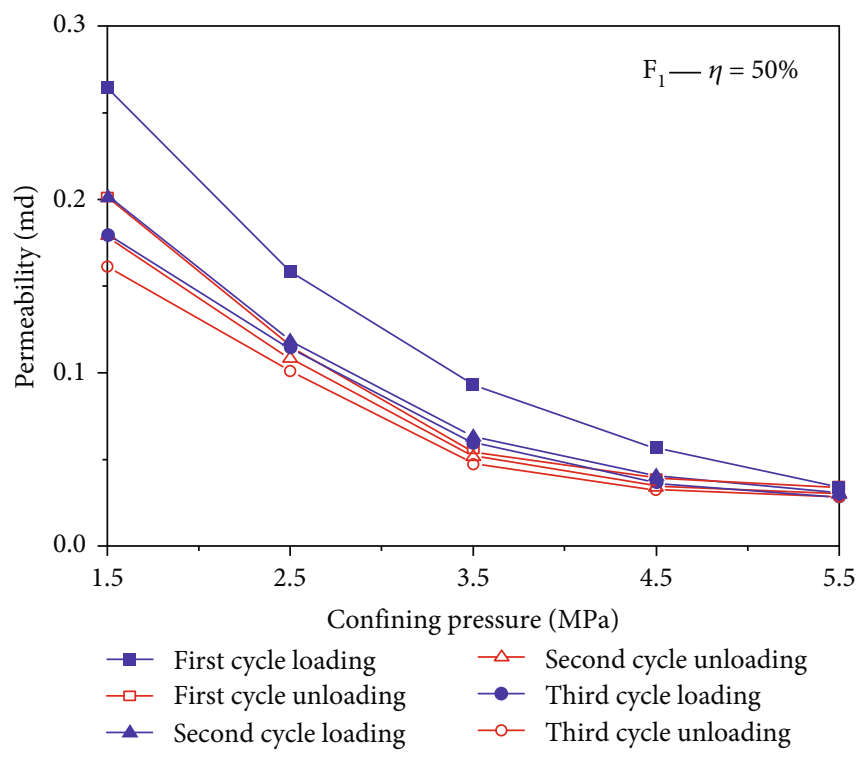

(c) $\eta=50 \%$

Figure 6: Continued. 


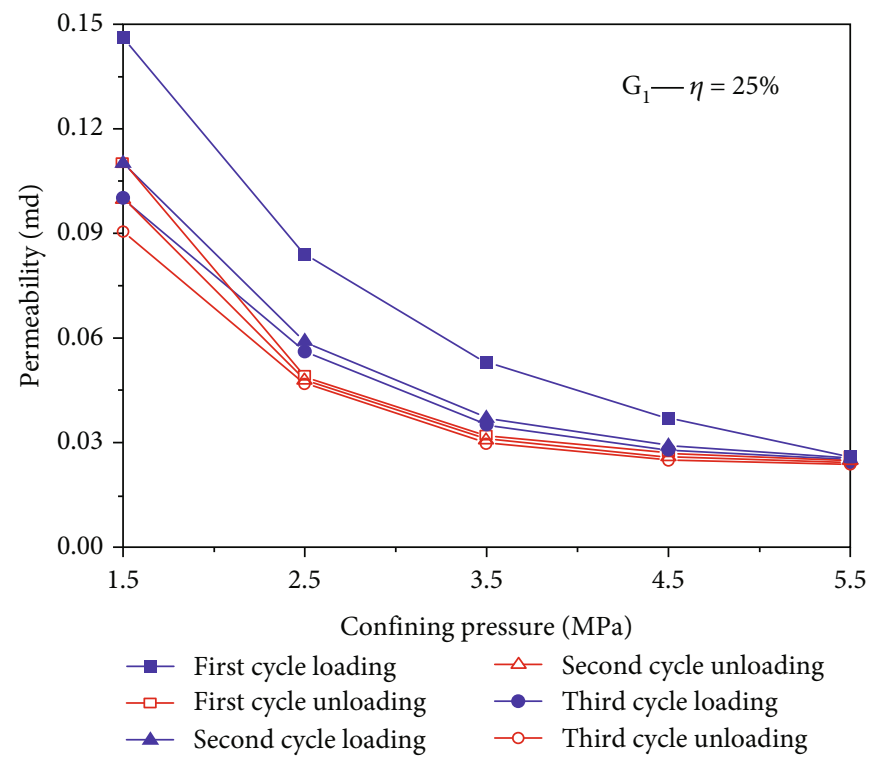

(d) $\eta=25 \%$

Figure 6: Relationship between permeability and confining pressure.

the following continuity equation, irrespective of the presence of joints in the rock mass or the degree of joint filling:

$$
\nabla \cdot v=0
$$

where $v$ is the seepage velocity.

The seepage fluid in a rock mass with joint fractures should satisfy the Navier-Stokes equation:

$$
-\nabla P+\eta \nabla^{2} v=\rho(v \cdot \nabla) \cdot v
$$

where $P, \eta$, and $\rho$ are the pressure, the dynamic viscosity, and the density of the fluid, respectively.

When joint fractures contain fillings, the difference between the permeabilities of the rock matrix and the fillings is incorporated into the rock seepage model using the Brinkman-extended Darcy equation [33]:

$$
-n \nabla P+\eta \nabla^{2} v-\frac{n \eta}{k v}=\frac{\rho}{n}(v \cdot \nabla) \cdot v,
$$

where $n$ and $k$ are the porosity and the permeability of the rock mass, respectively.

A steady-state method was used to determine the permeability in this study. An inlet air pressure was applied at the top of the sample, and the bottom of the sample was maintained at atmospheric pressure. Thus, a difference in the permeability pressure was created between the ends of the sample. The inlet air pressure $p$ and the outlet seepage quantity $Q$ were recorded by the pressure sensor and electronic flow meter, respectively. The gas flow in the rock mass was assumed to obey Darcy's law, and the permeability of the sample was calculated using $p$ and $Q$ col- lected using the abovementioned test. The calculation formula is as follows [26]:

$$
k=\frac{2 Q p \mu L}{\left(p^{2}-p_{0}^{2}\right) S},
$$

where $k$ is the permeability of the sample. $Q, p$, and $\mu$ are the seepage quantity, the import air pressure, and the dynamic viscosity of $\mathrm{N}_{2}$, respectively. $p_{0}$ denotes the atmospheric pressure. $L$ and $S$ represent the length and the cross-sectional area of the specimen, respectively.

\section{Results and Discussion}

3.1. Determination of Uniformity of Samples. The uniformity of the samples was assessed from the standard deviations in the density and permeability. The density differences were $0.015 \mathrm{~g} / \mathrm{cm}^{3}, 0.009 \mathrm{~g} / \mathrm{cm}^{3}, 0.001 \mathrm{~g} / \mathrm{cm}^{3}$, and $0.001 \mathrm{~g} / \mathrm{cm}^{3}$ for fractured samples with transfixion rates of $25 \%, 50 \%, 75 \%$, and $100 \%$, respectively. The permeabilities of the samples with different transfixion rates at a confining pressure of $1.5 \mathrm{MPa}$ are compared below.

The average permeability of samples with $25 \%, 50 \%$, $75 \%$, and $100 \%$ transfixion rates were $0.160 \mathrm{md}, 0.265 \mathrm{md}$, $1.026 \mathrm{md}$, and $2.402 \mathrm{md}$, respectively, and the corresponding standard deviations were $0.013 \mathrm{md}, 0.014 \mathrm{md}, 0.062 \mathrm{md}$, and $0.083 \mathrm{md}$. Table 1 and Figure 4 show that the fabricated samples meet the error requirements for the density and the initial permeability, ensuring the reliability of the subsequent analysis.

3.2. Effect of Transfixion Rate on Permeability. The permeabilities of the filled samples depend on the filling degree, filling angle, and transfixion rate. However, few studies have 


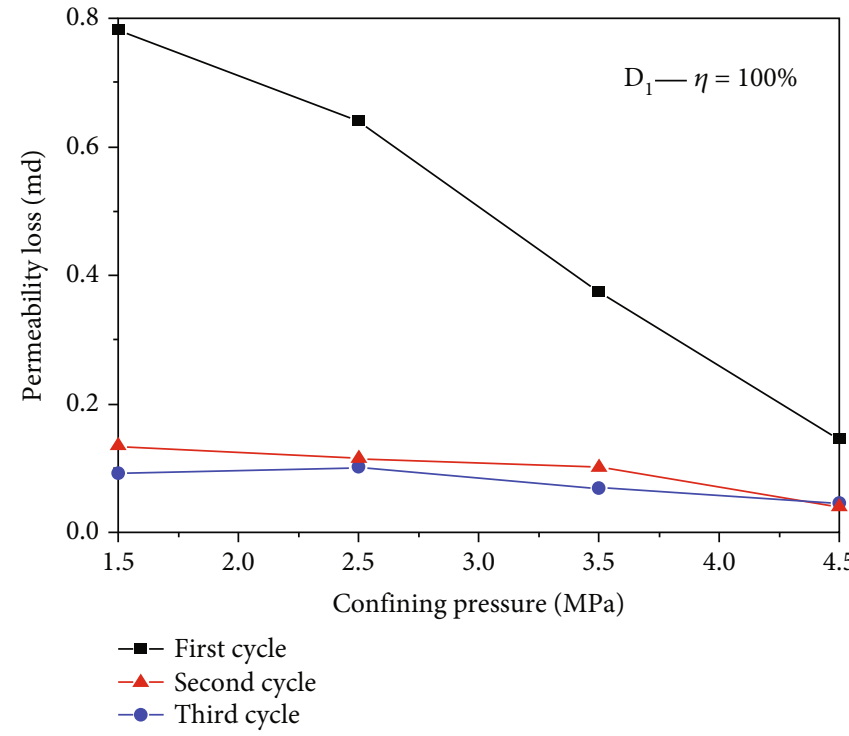

(a) $\eta=100 \%$

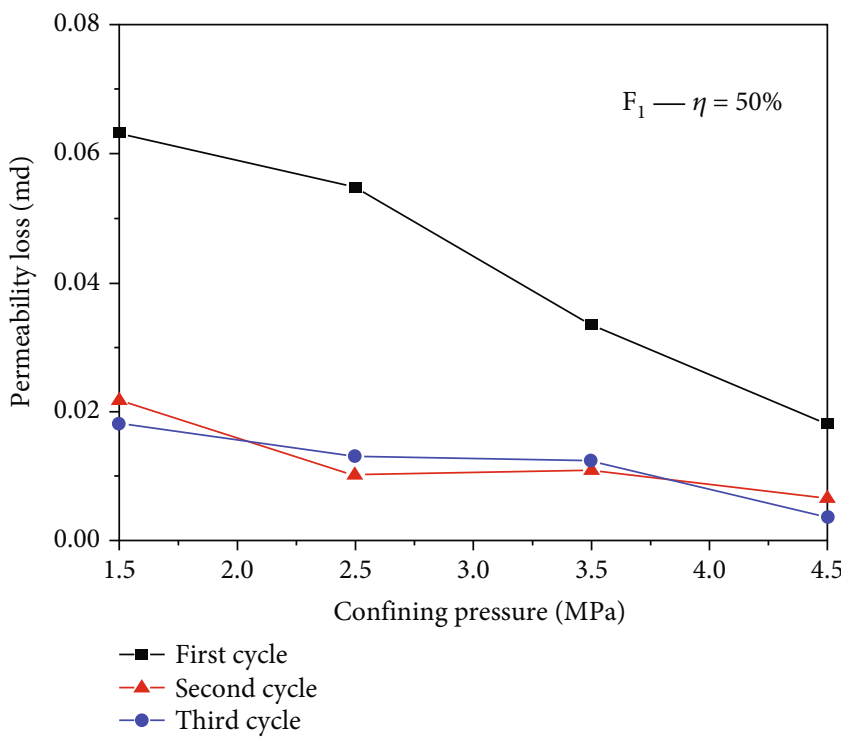

(c) $\eta=50 \%$

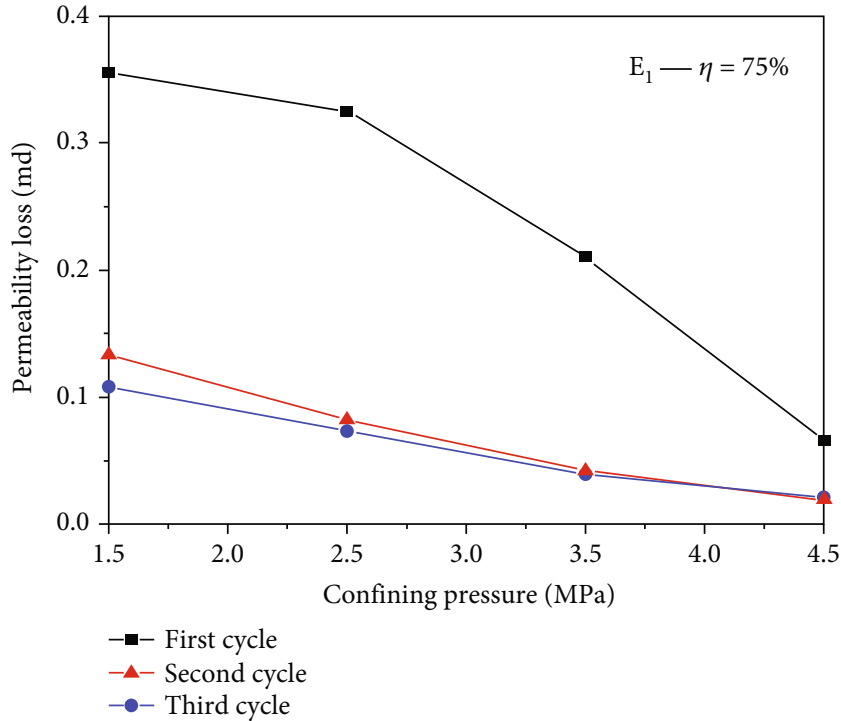

(b) $\eta=75 \%$

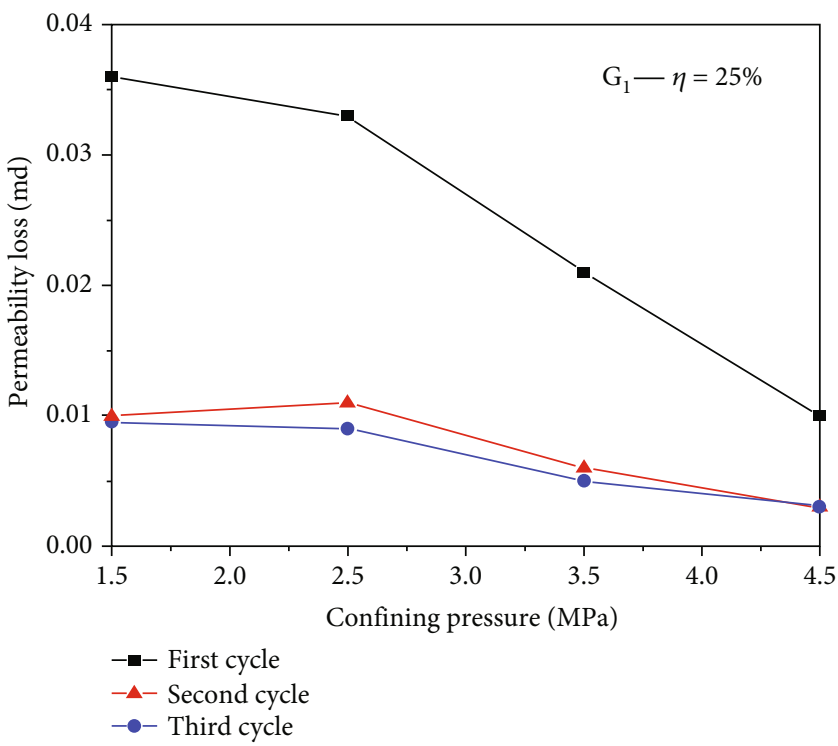

(d) $\eta=25 \%$

FIGURE 7: Relationship between permeability loss and confining pressure.

TABLE 2: Ratio of permeability loss during different cycle stages.

\begin{tabular}{lccc}
\hline No. & First cycle (\%) & Second cycle (\%) & Third cycle (\%) \\
\hline $\mathrm{D}_{1}$ & 71.15 & 15.62 & 13.23 \\
$\mathrm{E}_{1}$ & 65.43 & 17.94 & 16.63 \\
$\mathrm{G}_{1}$ & 64.16 & 18.88 & 16.96 \\
Average & 65.97 & 17.94 & 16.09 \\
\hline
\end{tabular}

been conducted to correlate the permeability of the fractured rock mass with the transfixion rate. The Mohr-Coulomb and Hoek-Brown strength criteria are generally used to describe the relationship among the principal stresses of a rock mass with incomplete transfixion. A test was carried out to determine the main permeability direction and thereby establish how the permeability of the samples depended on the transfixion rate.

Figure 5 shows that the permeability is an approximately exponential function in the transfixion rate, which can be fitted by the least squares method as follows:

$$
k=0.079 e^{3.448 \eta}-0.081,
$$

where $k$ is the permeability of the rock mass and $\eta$ is the transfixion rate.

As seen from Figure 5, for transfixion rates below 1/2, the slope of the permeability versus the transfixion rate curve is almost zero. However, the permeability increases linearly for transfixion rates above $1 / 2$. Thus, the transfixion rate of $1 / 2$ corresponds to an inflection point and can be regarded as a critical value. 
TABLE 3: Permeability recovery of different samples.

\begin{tabular}{lccc}
\hline No. & Recovery degree (\%) & No. & Recovery degree (\%) \\
\hline $\mathrm{D}_{1}$ & 68.55 & $\mathrm{D}_{2}$ & 68.68 \\
$\mathrm{E}_{1}$ & 51.31 & $\mathrm{E}_{2}$ & 65.29 \\
$\mathrm{~F}_{1}$ & 76.10 & $\mathrm{~F}_{2}$ & 77.21 \\
$\mathrm{G}_{1}$ & 69.55 & $\mathrm{G}_{2}$ & 75.34 \\
\hline
\end{tabular}

3.3. Variation in Permeability with Confining Pressure. As similar permeability curves were obtained for different samples with the same transfixion rate, only curves for samples $D_{1}, E_{1}, F_{1}$, and $G_{1}$ are presented in Figure 6 , the permeabilities of the samples decrease as the confining pressure increases during the loading stage, reflecting the effect of pore closure in the bedrock and fillings on the permeability. The slope of the permeability is steep during the early loading stage and decreases gradually as the confining pressure increases. The permeability increases as the confining pressure decreases during the unloading stage, reflecting the influence of pore opening in the bedrock and fillings on the permeability. The slope of the permeability is less steep during the initial unloading stage and increases gradually as the confining pressure decreases.

The permeability decreases nonlinearly as the transfixion rate decreases, and the confining pressure clearly affects the permeability. During the loading stage (1.5-3.5 MPa) and the unloading stage (3.5-1.5 MPa), the permeability is highly sensitive to the confining pressure, and the other confinement parameters have less of an effect on the permeability. This result is obtained because the pore structure of the filling provides the main seepage path during the initial stage of loading. As the confining pressure increases, the pores are gradually compressed, and the porosity of the filling decreases, closing the main seepage path and resulting in a lower rate of decrease in the permeability as the confining pressure increases.

At a later stage of loading, the samples undergo irreversible plastic deformation, and the seepage area extends over the cross-section of the entire sample. At this time, increasing the confining pressure has a relatively small effect on the seepage path, and the permeability decreases at an extremely low rate.

3.4. Analysis of Permeability Loss. The sample permeability differs during a single loading and unloading cycle at the same confining pressure. This difference is defined as the permeability loss, which directly characterizes the plastic deformation of the sample during the loading and unloading cycle. The permeability loss can be calculated as follows:

$$
\Delta k_{n}=k_{j n}-k_{x n},
$$

where $\Delta k_{n}$ is the permeability loss at the $n$-th confining pressure during the same loading and unloading cycle. $k_{j n}$ is the permeability at the $n$-th confining pressure during the loading phase. $k_{x n}$ is the permeability at the $n$-th confining pressure during the unloading phase.
The variation in the permeability loss with the cyclic confining pressure is only illustrated for samples $\mathrm{D}_{1}, \mathrm{E}_{1}, \mathrm{~F}_{1}$, and $G_{1}$, because almost identical results are obtained for samples with the same transfixion rate. Figure 7 shows that the permeability loss decreases as the confining pressure increases for samples with different transfixion rates, where the permeability loss changes most noticeably during the first cycle, and the same change trend is observed for subsequent cycles.

For a brittle sample, the permeability loss during the first loading cycle should be carefully considered. Taking the first cycle as an example, the permeability loss depends mainly on the intermittent time during which the load is exerted. Macroscopic changes occur from $1.5 \mathrm{MPa}$ during the loading stage to $1.5 \mathrm{MPa}$ during the unloading stage. The longest intermittent time during which the load is exerted and the highest permeability loss from plastic deformation occur over this period. The shortest load interval occurs from the loading stage at $4.5 \mathrm{MPa}$ to the unloading stage at $4.5 \mathrm{MPa}$; the lowest permeability loss is the lowest over this period and is intermediate for other confining pressures. Thus, there is a high/low permeability loss at low/high confining pressures. Most of the permeability loss mainly occurs during the first cycle and is proportional to the load interval time.

Table 2 shows the proportion of the permeability loss for the samples during different cycle stages. The permeability loss decreases gradually as the number of load cycles increases. Specifically, the average permeability loss during the first, second, and third cycles is $65.97 \%, 17.94 \%$, and $16.09 \%$, respectively. That is, the permeability loss during the first cycle is 3.68 and 4.10 times that during the second and third cycles, respectively. When a sample with different transfixion rates is subjected to a multicycle load under a low confining pressure, most of the permeability loss occurs during the first cycle, and similar and small permeability losses occur during subsequent cycles.

An analysis of the dependence of the permeability on the confining pressure shows that the variation in the permeability is considerably higher during the first cycle stage than during subsequent cycles. The recovery degree of the permeability after unloading the confining pressure is quantified by the ratio of the permeability during the unloading stage of the first cycle to that during the loading stage at a confining pressure of $1.5 \mathrm{MPa}$ :

$$
\Delta k_{r}=\frac{k_{x 1}}{k_{j 1}},
$$

where $\Delta k_{r}$ is the recovery degree of the permeability. $k_{x 1}$ and $k_{j 1}$ are the permeabilities of the sample during the unloading and loading stages of the first cycle at a confining pressure of $1.5 \mathrm{MPa}$, respectively.

Table 3 shows that when the maximum confining pressure does not exceed the filling strength, there is over $65 \%$ recovery of the permeability of samples with different transfixion rates. As the filling remains in the elastic-plastic state under a low confining pressure, there is high recovery of the internal pore structure of the sample after unloading the cyclic confining pressure. 


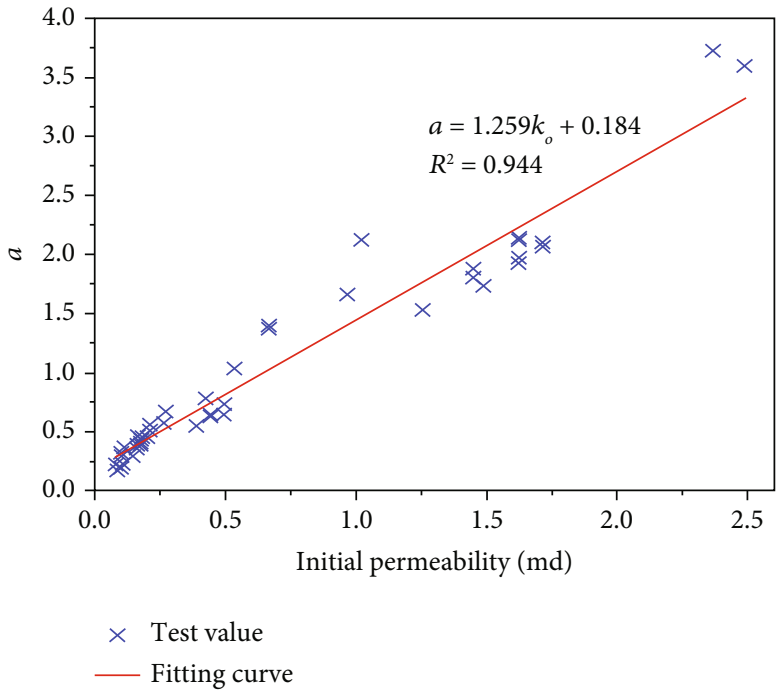

(a) Coefficient $a$

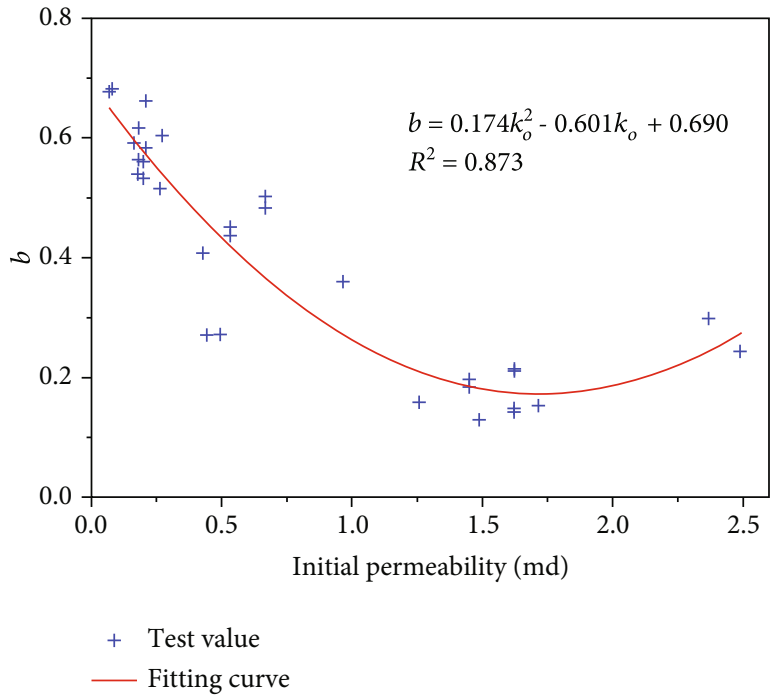

(b) Coefficient $b$

FIgURE 8: Coefficients $a$ and $b$ with variation of initial permeability.

3.5. Functional Relationship between Permeability and Confining Pressure. Various functions were used to fit scatter plots of the permeability versus the confining pressure for samples with different transfixion rates. A high fitting degree was obtained using the following power law for the constitutive relation:

$$
k=a P^{-b},
$$

where $P$ is the confining pressure. $a$ and $b$ are regression coefficients.

Most of the fitting degrees obtained using Equation (8) to fit the permeability as a function of the confining pressure at different loading and unloading stages for the three cycles are above $90 \%$.

The initial permeability $k_{o}$ for each stage is defined as permeability of the sample at a $1.5 \mathrm{MPa}$ confining pressure. The least squares method is used to fit the coefficients $a$ and $b$ with functions of $k_{o}$, resulting in the following constitutive relations:

$$
\begin{gathered}
a=m k_{o}+n, \\
b=\lambda k_{o}^{2}+\beta k_{o}+\gamma,
\end{gathered}
$$

where $k_{o}$ is the initial permeability. $m, n, \lambda, \beta$, and $\gamma$ are regression coefficients. The coefficients $a$ and $b$ are related to the initial permeability of the sample, as shown in Figure 8.

The coefficient $a$ increases linearly with the initial permeability, that is, the higher the initial permeability is, the larger $a$ is. The coefficient $b$ measures how sensitive the initial permeability of the sample is to the confining pressure: the value of $b$ for the loading stage shows that the sample pores gradually closed as the confining pressure increased, and the value of $b$ for the unloading stage shows that the internal pore structure of the sample was partially restored as the confining pressure was reduced.
The sensitivity of the permeability to the confining pressure for samples with different transfixion rates during the loading and unloading stages is relative. The macroscopic results show that the sensitivity of pore closure and opening to the confining pressure decreases gradually as the number of loading cycles increases.

3.6. Relationship between Permeability and Stress Sensitivity Coefficient. It is challenging to individually assess the numerous factors affecting the permeability of filled samples. The sensitivity of the permeability to the confining pressure is quantitatively analyzed by normalizing the permeability to obtain the following expression for the stress sensitivity coefficient [34].

$$
C_{k}=-f^{\prime}(k) k_{o}^{-1}
$$

where $C_{k}$ is the sensitivity coefficient of the permeability to the confining pressure. Using Equation (8), $f(k)$ can be expressed as follows:

$$
f^{\prime}(k)=a b P^{(b-1)} .
$$

An analytical expression for $C_{k}$ is obtained by substituting Equation (11) into Equation (10).

$$
C_{k}=-k_{o}^{-1} \frac{\partial k}{\partial p}=-k_{o}^{-1} a b P^{(b-1)},
$$

where $a$ and $b$ are the regression coefficients. $P$ is the corresponding confining pressure. $k_{o}$ is the initial permeability of the sample at the considered stage.

The sensitivity coefficient is a quantitative measure of the sensitivity of the permeability to the confining pressure. The permeabilities at different confining pressures are used to formulate an expression for the permeability sensitivity coefficient as a function of the confining pressure, and the resulting curve 


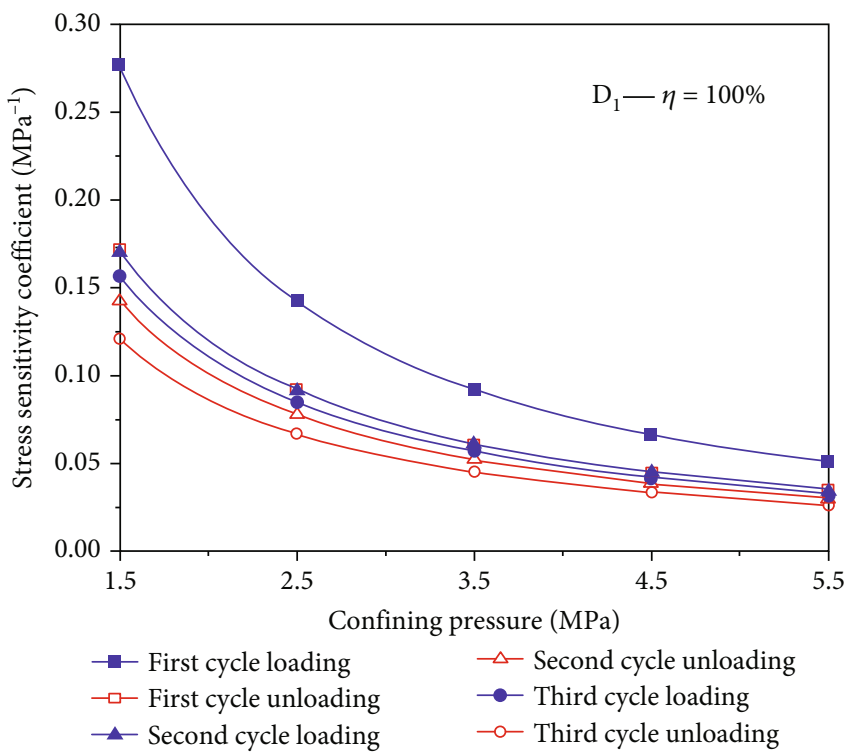

(a) $\eta=100 \%$

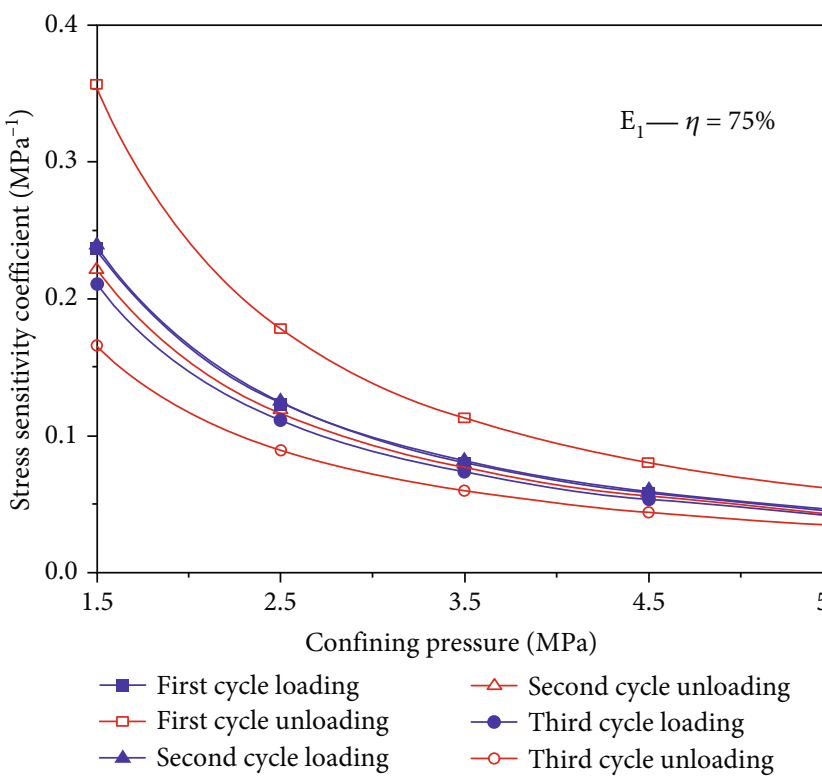

(b) $\eta=75 \%$

FIgURE 9: Continued. 


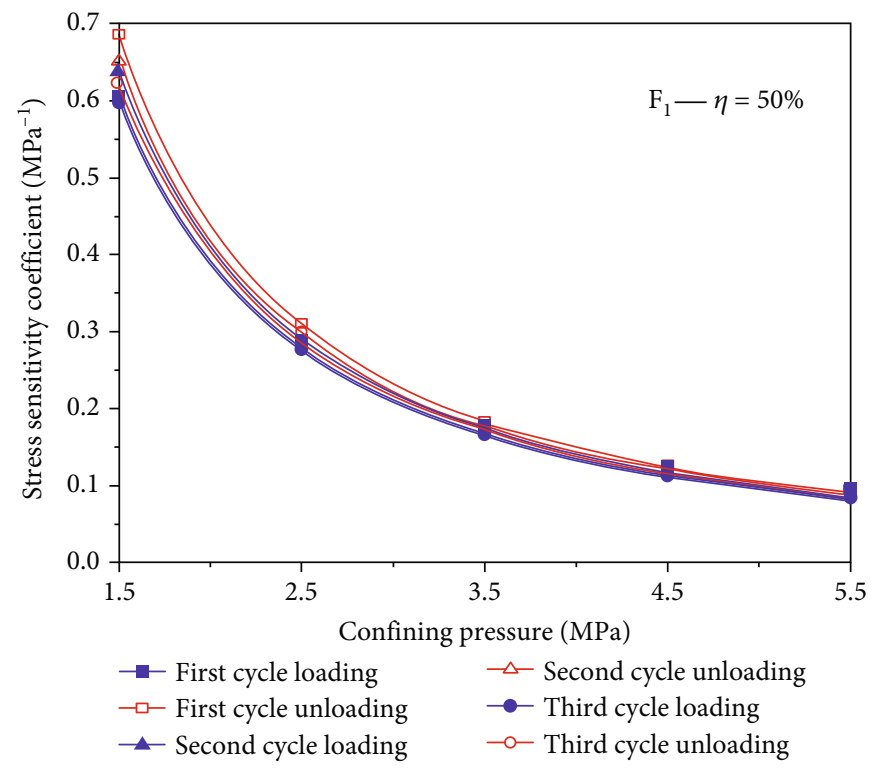

(c) $\eta=50 \%$

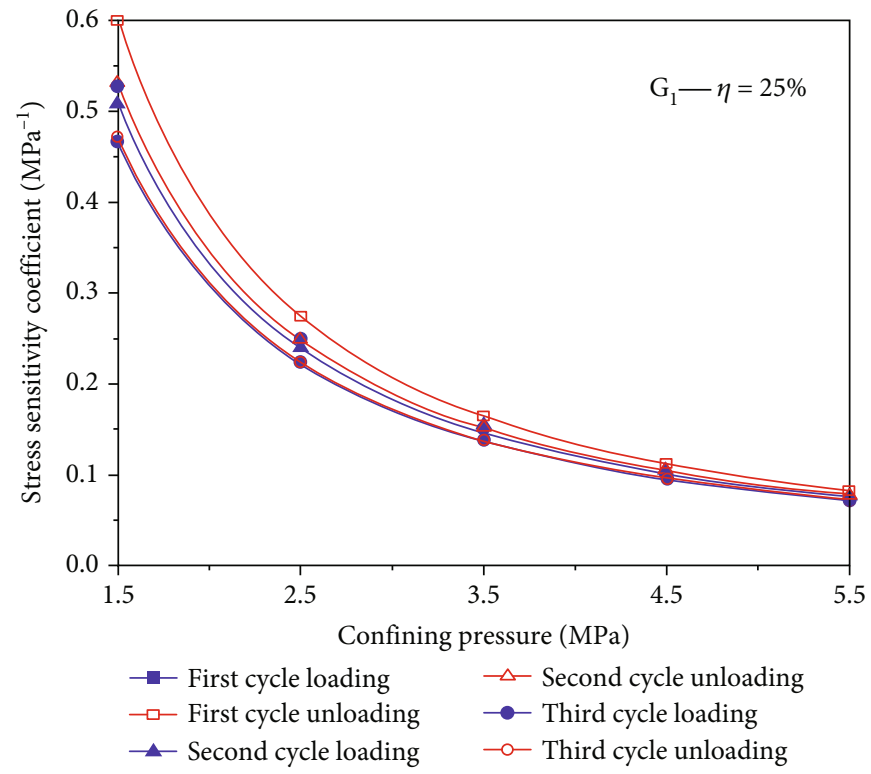

(d) $\eta=25 \%$

FiguRE 9: Variation curves of stress sensitivity coefficients and confining pressure.

is shown in Figure 9. As seen from Figure 9, after several loading cycles of the confining pressure, the stress sensitivity coefficient decreases as the confining pressure increases for samples with different transfixion rates. The stress sensitivity coefficient changes at a smaller rate than the confining pressure for large confining pressures (above $3.5 \mathrm{MPa}$ ). In the fully penetrated samples, the filling is subjected to all the applied stresses: thus, the first confining pressure loading cycle causes significant closure of the internal pores, such that the stress sensitivity coefficient cannot be fully recovered after the first unloading cycle. The recovery degree of the stress sensitivity coefficient in the subsequent two cycles is larger than for the first cycle, where the stress sensitivity coefficient is lower during the unloading stage than during the loading stage.
As the transfixion rate decreases, the sample matrix protects the filling during the application of the confining pressure, such that the stress sensitivity coefficient can be completely recovered after unloading the confining pressure, and the stress sensitivity coefficient is higher during the unloading stage than during the loading stage. This result shows that the stress sensitivity coefficient of the sample is affected by the presence of the filling fracture. The recovery degree of the stress sensitivity coefficient is affected by the transfixion rate. The lowest recovery degree for the stress sensitivity coefficient is obtained for the sample with complete transfixion; the maximum stress sensitivity coefficient of samples with different transfixion rates does not necessarily occur during the loading stage, 

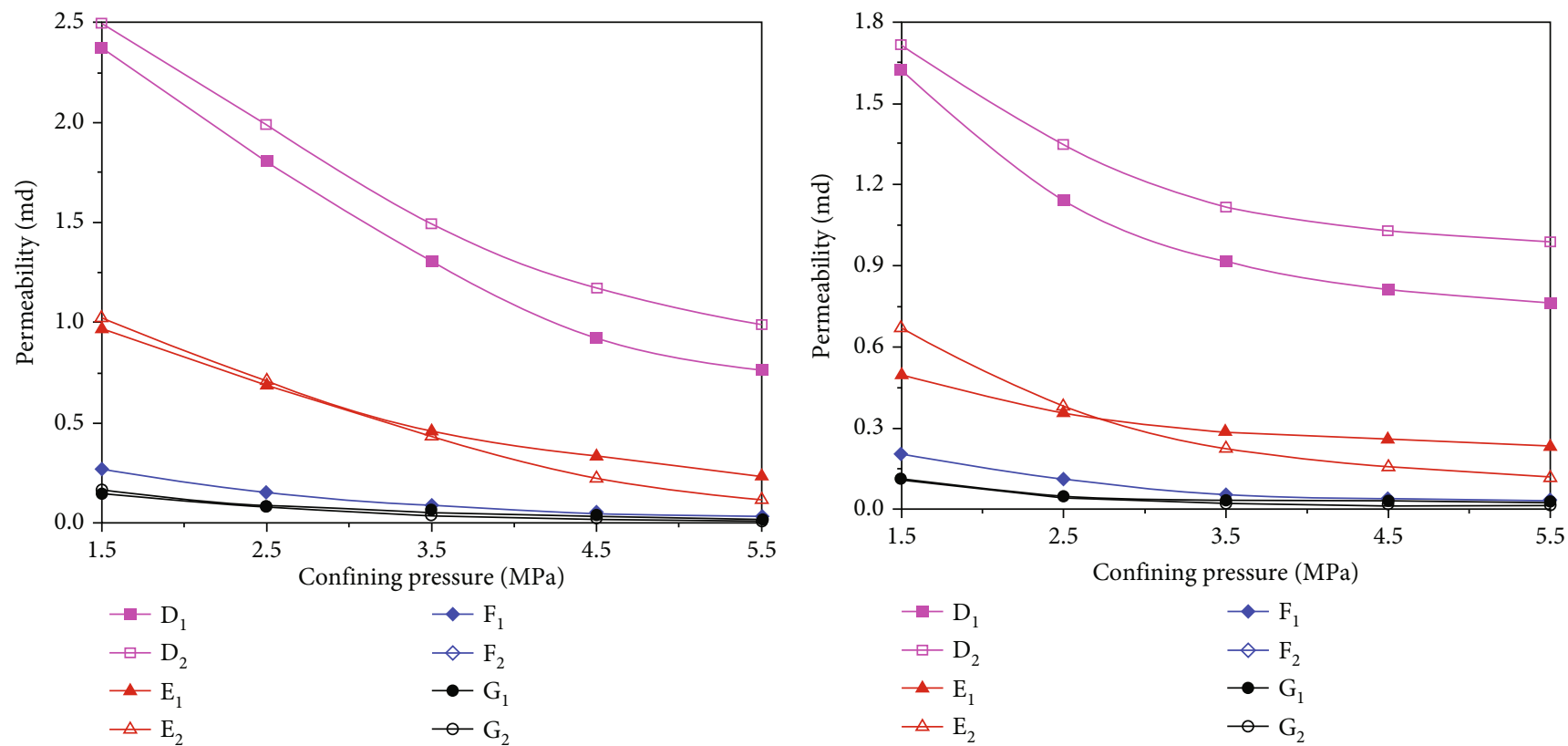

(a) Loading for first cycle

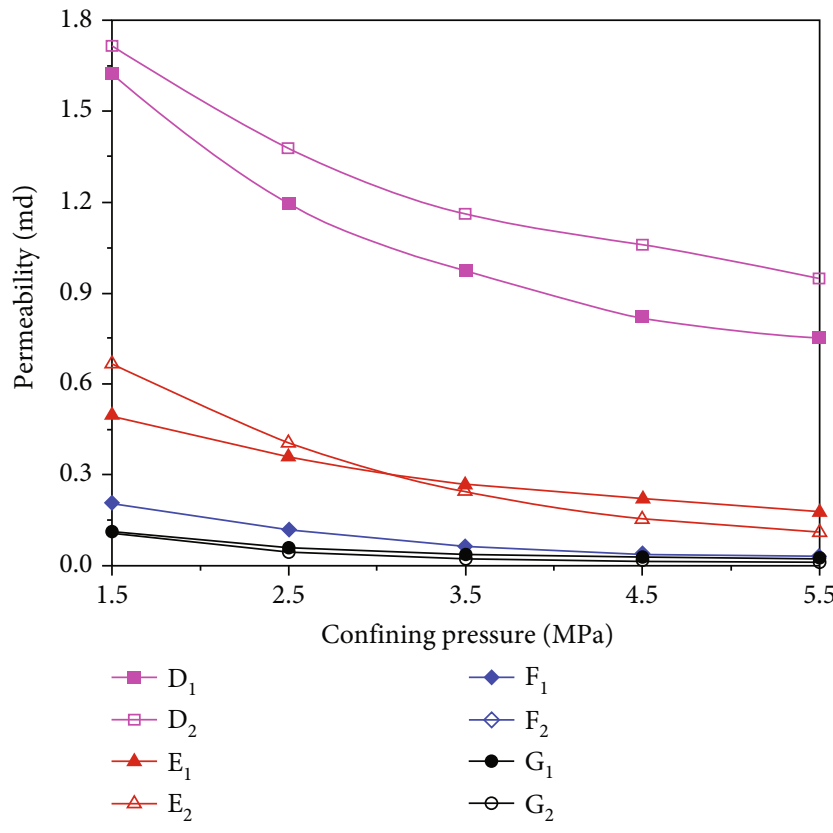

(c) Loading for second cycle (b) Unloading for first cycle

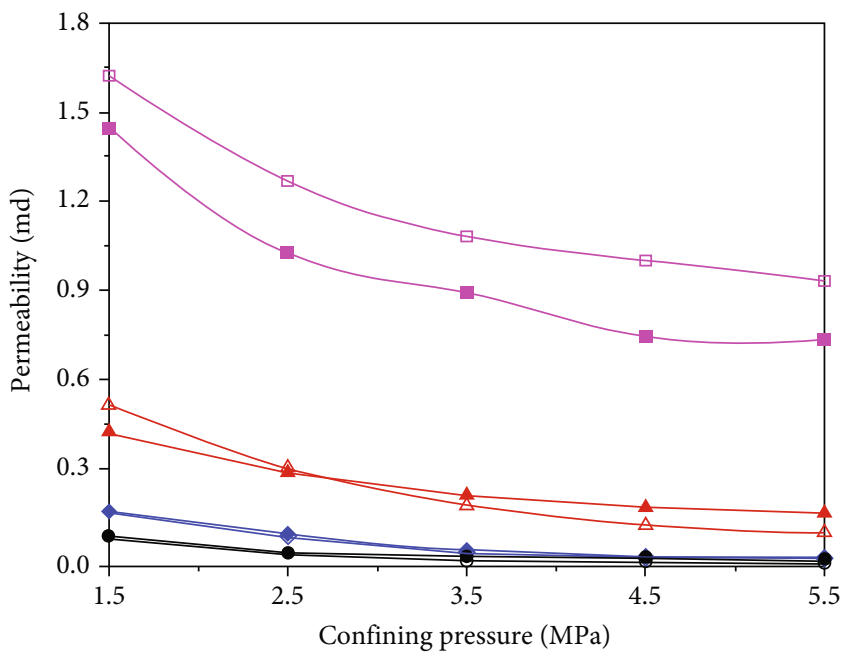

(d) Unloading for second cycle

FIgUre 10: Continued. 


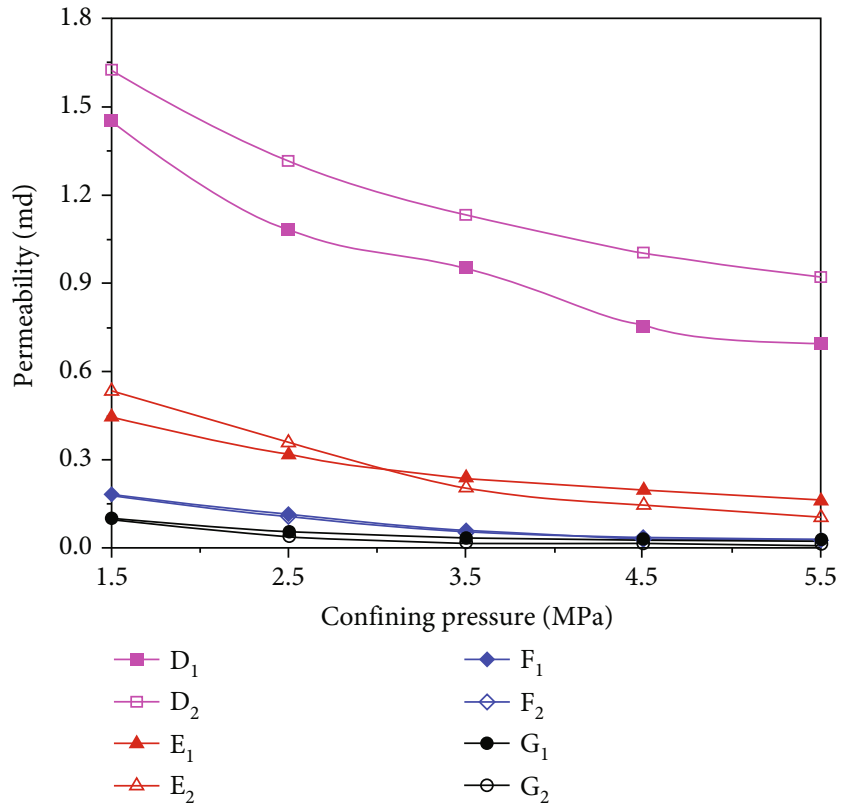

(e) Loading for third cycle

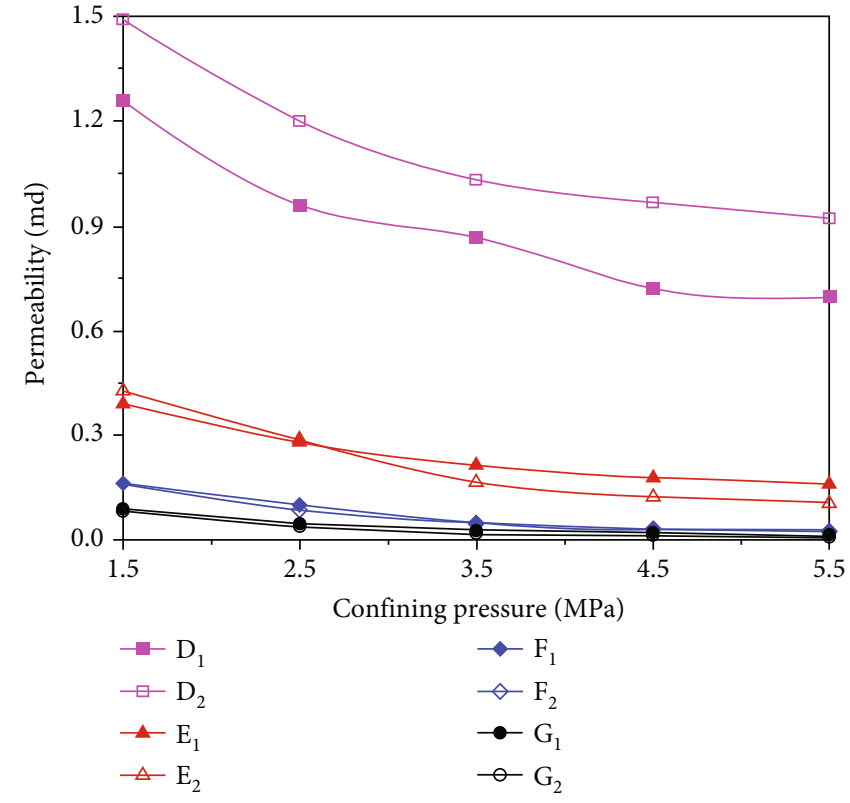

(f) Unloading for third cycle

Figure 10: Permeability differences of samples under different confining pressures.

and the stress sensitivity coefficient may be higher during the unloading stage than during the loading stage.

3.7. Analysis of Changes in Permeability. Figure 10 shows that the permeabilities of different samples decrease as the confining pressure increases for all stages. The permeability of the sample with complete transfixion is clearly higher than that of other samples, where the sample with a $75 \%$ transfixion rate has an intermediate permeability, and there is no discernable permeability difference between samples with transfixion rates less than half the sample height. These results show that the degree of transfixion of the filling affects the sample permeability, where the larger the transfixion rate is, the higher the permeability is. The permeability changes most noticeably for transfixion rates above one-half. Quantitatively, the initial permeability of samples $\mathrm{D}_{1}, \mathrm{D}_{2}, \mathrm{E}_{1}, \mathrm{E}_{2}, \mathrm{~F}_{1}, \mathrm{~F}_{2}, \mathrm{G}_{1}$, and $\mathrm{G}_{2}$ during the first cycle loading stage is $2.37 \mathrm{md}$, $2.49 \mathrm{md}, 0.97 \mathrm{md}, 1.02 \mathrm{md}, 0.26 \mathrm{md}, 0.27 \mathrm{md}, 0.14 \mathrm{md}$, and $0.16 \mathrm{md}$, respectively.

The order of magnitude of the permeability does not change between samples with transfixion rates of $100 \%$ and $75 \%$, and there is a very small difference between the permeability of samples with transfixion rates of $50 \%$ and $25 \%$. For a filled fracture, the permeability of the sample is affected by the transfixion rate, and a critical transfixion rate is observed. The permeability of samples with transfixion rates above one-half is approximately 8.25 times that of samples with transfixion rates below one-half.

\section{Conclusions}

A low-permeability coal-rock triaxial seepage device was used to carry out tests to study the seepage behaviour of the filled samples using different transfixion rates under cyclic loading and unloading of the confining pressure. The main conclusions are given below.

(1) Under cyclic loading and unloading of low confining pressures, the permeability of the filled sample increases approximately exponentially with the transfixion rate. The permeability decreases as the confining pressure increases during the loading stage but increases as the confining pressure decreases during the unloading stage

(2) The stress sensitivity coefficient of the sample permeability decreases as the confining pressure increases: For samples with complete transfixion, the stress sensitivity coefficient cannot be completely restored after unloading the confining pressure. For samples with incomplete transfixion, the stress sensitivity coefficient during the unloading stage is higher than that during the loading stage

(3) For samples with different transfixion rates, the permeability is a power function and mainly changes at low confining pressures. Both the permeability and the permeability loss increase with the transfixion rate and change more noticeably when the transfixion rate is above one-half the sample height

Fractures occur irregularly in natural rock masses, resulting in diverse types of filling. The further study is to construct the fractured model infilling with different occurrences by using novel technological schemes, considering the seepage behaviour under thermo-hydraulic-mechanical coupling conditions. 


\section{Data Availability}

The data in the paper can be open, and the readers can access the data with just the Journal's permission. Data sharing allows researchers to verify the results of an article, replicate the analysis, and conduct secondary analyses, so there are not any restrictions on data access. All the data used to support the findings of this study are included within the article.

\section{Conflicts of Interest}

The authors declare that they have no conflicts of interest.

\section{Acknowledgments}

This work was supported by the National Natural Science Foundation of China (51774112) and the Fundamental Research Funds for the Universities of Henan Province (NSFRF200202).

\section{References}

[1] M. G. Sweetenham, R. M. Maxwell, and P. M. Santi, "Assessing the timing and magnitude of precipitation-induced seepage into tunnels bored through fractured rock," Tunnelling and Underground Space Technology, vol. 65, pp. 62-75, 2017.

[2] P. Duffaut, "The traps behind the failure of Malpasset arch dam, France, in 1959," Journal of Rock Mechanics and Geotechnical Engineering, vol. 5, no. 5, pp. 335-341, 2013.

[3] Q. X. Meng, W. Y. Xu, H. L. Wang, X. Y. Zhuang, W. C. Xie, and T. Rabczuk, "DigiSim - an open source software package for heterogeneous material modeling based on digital image processing," Advances in Engineering Software, vol. 148, article 102836, 2020.

[4] M. Zhang, K. Feng, K. Zhang, Z. Zhao, and Y. Cao, “Transient characteristics of a straight tube actuated by viscous compressible flow with consideration of large axisymmetric deformation," Acta Mechanica, vol. 230, no. 1, pp. 105-120, 2019.

[5] B. Mehdipour, H. Hashemolhosseini, B. Nadi, and M. Mirmohamadsadeghi, "Investigating the effect of geocell changes on slope stability in unsaturated soil," Tehnički Glasnik, vol. 14, no. 1, pp. 66-75, 2020.

[6] E. Mohtarami, A. Baghbanan, M. Akbariforouz, H. Hashemolhosseini, and E. Asadollahpour, "Chemically dependent mechanical properties of natural andesite rock fractures," Canadian Geotechnical Journal, vol. 55, no. 6, pp. 881893, 2018.

[7] A. Khosravi, M. H. Sadaghiani, M. Khosravi, and C. L. Meehan, "The effect of asperity inclination and orientation on the shear behavior of rock joints," Geotechnical Testing Journal, vol. 36, no. 3, p. 20120060, 2013.

[8] R. Yang, T. Ma, W. Liu, Y. Fang, and L. Xing, "Coupled hydromechanical analysis of gas production in fractured shale reservoir by random fracture network modeling," International Journal of Applied Mechanics, vol. 11, no. 3, article 1950031, 2019.

[9] P. P. Luo, S. R. Wang, P. Hagan, Q. X. Huang, C. Cao, and K. Gamage, "Mechanical performances of cement-gypsum composite material containing a weak interlayer with different angles," DYNA, vol. 94, no. 1, pp. 447-454, 2019.
[10] M. Drapaluk, "Influence of reinforced concrete forming features on mechanical characteristics," Tehnički Glasnik, vol. 13, no. 2, pp. 86-91, 2019.

[11] P. Saiz, D. Ferrandez, C. Moron, and F. Fernandez, "Behaviour of masonry mortars fabricated with recycled aggregate towards," DYNA, vol. 94, no. 4, pp. 442-446, 2019.

[12] S. Levasseur, R. Charlier, B. Frieg, and F. Collin, "Hydromechanical modelling of the excavation damaged zone around an underground excavation at Mont Terri rock laboratory," International Journal of Rock Mechanics and Mining Sciences, vol. 47, no. 3, pp. 414-425, 2010.

[13] B. Li, R. Bao, Y. Wang, R. Liu, and C. Zhao, "Permeability evolution of two-dimensional fracture networks during shear under constant normal stiffness boundary conditions," Rock Mechanics and Rock Engineering, vol. 54, no. 1, pp. 409-428, 2021.

[14] T. Takemura, M. Osada, Y. Fujii, T. Kanamaru, and M. Takahashi, "Hydraulic properties of a single rock fracture filled by calcite," Journal of the Japan Society of Engineering Geology, vol. 51, no. 2, pp. 92-96, 2010.

[15] F. Ye, J. C. Duan, W. X. Fu, and X. Y. Yuan, "Permeability properties of jointed rock with periodic partially filled fractures," Geofluids, vol. 2019, no. 4, 14 pages, 2019.

[16] C. L. Wang, X. D. Zhang, G. Z. Li, Z. G. Du, and S. Zhang, "Experimental study on the permeability of coal samples with different heights under cyclic loading and unloading," Chinese Journal of Rock Mechanics and Engineering, vol. 37, no. 10, pp. 2299-2308, 2018.

[17] P. Mamot, S. Weber, T. Schroder, and M. Krautblatter, "A temperature- and stress-controlled failure criterion for icefilled permafrost rock joints," The Cryosphere, vol. 12, no. 10, pp. 3333-3353, 2018.

[18] M. H. Salimian, A. Baghbanan, H. Hashemolhosseini, M. Dehghanipoodeh, and S. Norouzi, "Effect of grouting on shear behavior of rock joint," International Journal of Rock Mechanics and Mining Sciences, vol. 98, pp. 159-166, 2017.

[19] B. Indraratna, W. Premadasa, E. T. Brown, A. Gens, and A. Heitor, "Shear strength of rock joints influenced by compacted infill," International Journal of Rock Mechanics and Mining Sciences, vol. 70, pp. 296-307, 2014.

[20] H. Jahanian and M. H. Sadaghiani, "Experimental study on the shear strength of sandy clay infilled regular rough rock joints," Rock Mechanics and Rock Engineering, vol. 48, no. 3, pp. 907922, 2015.

[21] Y. Lu, L. Wang, Z. Li, and H. Sun, "Experimental study on the shear behavior of regular sandstone joints filled with cement grout," Rock Mechanics and Rock Engineering, vol. 50, no. 5, pp. 1321-1336, 2017.

[22] C. X. She and F. T. Sun, "Study of the peak shear strength of a cement-filled hard rock joint," Rock Mechanics and Rock Engineering, vol. 51, no. 3, pp. 713-728, 2018.

[23] Y. Wang, W. K. Feng, R. L. Hu, and C. H. Li, "Fracture evolution and energy characteristics during marble failure under triaxial fatigue cyclic and confining pressure unloading (FCCPU) conditions," Rock Mechanics and Rock Engineering, vol. 54, pp. 799-818, 2021.

[24] Z. Tao, C. Zhu, M. He, and M. Karakus, "A physical modelingbased study on the control mechanisms of Negative Poisson's ratio anchor cable on the stratified toppling deformation of anti-inclined slopes," International Journal of Rock Mechanics \& Mining Sciences, vol. 138, article 104632, 2021. 
[25] S. Fereshtenejad and J.-J. Song, "Fundamental study on applicability of powder-based 3D printer for physical modeling in rock mechanics," Rock Mechanics and Rock Engineering, vol. 49, no. 6, pp. 2065-2074, 2016.

[26] K. Zhao, H. L. Wang, W. Y. Xu, and J. Xia, "Experimental study on seepage characteristics of rock-like materials with consecutive and filling fractures," Chinese Journal of Rock Mechanics and Engineering, vol. 39, no. 6, pp. 1130-1136, 2017.

[27] P. F. Wang, W. H. Tan, X. W. Ma, Z. J. Li, J. J. Liu, and Y. F. $\mathrm{Wu}$, "Experimental study on seepage characteristics of consecutive and filling fracture with different roughness and gapwidth," Rock and Soil Mechanics, vol. 40, no. 8, pp. 30623070, 2019.

[28] D. Head and T. Vanorio, "Effects of changes in rock microstructures on permeability: 3-D printing investigation," Geophysical Research Letters, vol. 43, no. 14, pp. 7494-7502, 2016.

[29] H. Bejari and J. K. Hamidi, "Simultaneous effects of joint spacing and orientation on TBM cutting efficiency in jointed rock masses," Rock Mechanics and Rock Engineering, vol. 46, pp. 997-1004, 2013.

[30] S. R. Wang, X. G. Wu, Y. H. Zhao, P. Hagan, and C. Cao, "Evolution characteristics of composite pressure-arch in thin bedrock of overlying strata during shallow coal mining," International Journal of Applied Mechanics, vol. 11, no. 3, article 1950030, 2019.

[31] C. Rogers, "On Stefan-type moving boundary problems with heterogeneity: canonical reduction via conjugation of reciprocal transformations," Acta Mechanica, vol. 230, no. 3, pp. 839850, 2019.

[32] C. Zhu, M. He, M. Karakus, X. Zhang, and Z. Tao, "Numerical simulations of the failure process of anaclinal slope physical model and control mechanism of negative Poisson's ratio cable," Bulletin of Engineering Geology and the Environment, vol. 80, no. 4, pp. 3365-3380, 2021.

[33] C. Deng and D. M. Martinez, "Viscous flow in a channel partially filled with a porous medium and with wall suction," Chemical Engineering Science, vol. 60, no. 2, pp. 329-336, 2005.

[34] Z. M. Chao, H. L. Wang, W. Y. Xu, H. Ji, and K. Zhao, "Permeability and porosity of columnar jointed rock under cyclic loading and unloading," Chinese Journal of Rock Mechanics and Engineering, vol. 36, no. 1, pp. 124-140, 2017. 